\section{How the Thymectomy for Myasthenia Gravis Practice Parameter was Developed}

\author{
Richard J. Barohn, MD
}

Recently, Dr. Nicholas Brennecke, a neuromuscular fellow at Case Western in Cleveland asked me if I could give him some background information on how the thymectomy practice parameter was developed. ${ }^{1}$ He was preparing a talk on thymectomy in myasthenia gravis (MG) and he asked if I “could give me a 'front row seat' on your experience during these years." This prompted me to write him the following story.

I first had the idea to do a randomized thymectomy study in the late 1980s when I was at UTHSC-San Antonio. I presented the idea at the yearly MGA conference to a group of senior doctors in Chicago on a cold December day. I called the presentation MY GRANTs: Myasthenia GRavis RaNdomized Thymectomy study. They were very skeptical and said, "Young man, there is no need for the study, and you should focus your time on something worthwhile and more productive."

I did not give up. I continued to try to put together a group of doctors in the USA in the 90s who wanted to do a randomized thymectomy study. I wrote a protocol and developed a new classification system for MG and I also developed the first version of the Myasthenia GravisActivities of Daily Living (MG-ADL) scale for the thymectomy project. ${ }^{2}$ We found the original protocol I wrote with Dr. Carlayne Jackson who was my first neuromuscular fellow at UTHSC (San Antonio.) The protocol is dated 4-15-93. I am including it in this issue immediately after these comments in the "proposed stuff - old stuff” category. In this version, we had developed the initial version of the MG-ADL (later modified by Gil Wolfe and Laura Herbelin and I at UTSW.) This protocol also included our attempts at coming up with a new MG grading scale to replace the old osserman scale. I liked this scale, but it did not catch on and instead a committee of the MG Foundation of America through a consensus conference I was on developed the MGFA-MG grading scale which is widely accepted. ${ }^{3}$ I had meetings at several American Academy of Neurology (AAN) annual meetings with interested neurologists to discuss the protocol. But I could never get it off the ground very far. I moved to University of Texas - Southwestern (UTSW) in Dallas in 1993 and I took the "advice" from the senior neurologists I originally pitched the idea to: work on something I could accomplish. I began working on an intravenous immune globulin (IVIG)-randomized MG study. Gil Wolfe had just arrived at UTSW in 1994 and he worked with me on the IVIG-MG project. We got an FDA-
OPD grant and an MDA grant to fund that study, which was ultimately aborted early due to a nationwide IVIG shortage.

In the late 90s, two things happened. Dr. John NewsomDavis contacted me from Oxford, England and said he wanted to put together such a study on an international level. He was a senior myastheniologist and I had the feeling he could pull it off where I could not. He asked me to help. I was very busy doing other things at UTSW, and I had just become interim chair of the Department of Neurology. I told him to work with my partner Gil Wolfe instead as his U.S. partner and he did. Around the same time I was asked to put together a practice parameter on MG by the AAN. This was in the very early stages of practice parameter development. They did not tell me which topic in MG to tackle. So, I decided to tackle the thymectomy issue. I did not know how to write a practice parameter. But my close colleague from my U.S. Air Force days was Dr. Gary Gronseth who was then the chair of neurology at Wilford Hall U.S. Air Force Medical Center in San Antonio. This was where I had served on active duty in the military and I was still in the USAF reserved and did my reserve training and time there. Gary was on the ground floor of teaching doctors how to write practice parameters, and since were already friends and colleagues, I was able to work closely with him to pull it off. I gathered all the literature up to the late 1990s. I sat down with Gary in his office at Wilford Hall and we went through each one. He showed me how to classify them as Class 1, 2, 3, etc. All the literature were retrospective reviews. We found the ones that did comparisons of groups that had thymectomy and ones that did not. We found about 25 articles out of hundreds of thymectomy reports. We gathered the outcomes data from these papers and made our best guess as to what the outcomes were. Of course, there was no standardized definition of MG outcomes at this time. Each report had their own definition of remission, improvement, etc. But we did the best we could. At the end of the analysis, it did look like perhaps the thymectomy group did a bit better. But there were many confounders which made us conclude that we needed a true prospective randomized controlled trial. Fortunately, Dr. NewsomDavis was already putting together an international team to write the NIH grant to fund such a study. Also, at the same time that the thymectomy practice parameter came out, I had been asked to serve on a committee to come up with a new classification of MG (to replace outdated versions) and to come up with recommendations for assessing $\mathrm{MG}$ outcomes. This paper came out in the same year (perhaps in the same issue) of Neurology. So the ground work was laid for the thymectomy study.

I was always a skeptic regarding the effect of thymectomy in MG. My mentor Dr. Jerry Mendell first instilled this 
skepticism into me as a young fellow in 1986-87. He had presented a talk at the AAN in the mid-1980s raising the question of "Does thymectomy work for MG?" He was not the first to raise this question. Dr. Michael McQuillen when at the University of Kentucky wrote a paper in Neurology called "A Treatment Carol: Thymectomy Revisited" when he reviewed data from prior published trials raising the possibility that we did not have sufficient data to advocate for thymectomy in MG. This was in $1977 .{ }^{5}$ One of his protégés Dr. Doug Lanska wrote a similar editorial in Neurology in the early 90 s. $^{6}$

Based on this background, I was not convinced thymectomy for MG was an effective procedure based on all the retrospective data that had been reported. And we all had patients in our clinics who had thymectomies but were still very symptomatic on therapy. Then the international community led by Dr. Newsom-Davis did the study and you know the rest of the story. It was spectacularly positive showing thymectomy definitely benefits patients with MG. I became a believer and I now recommend it to most of my generalized MG patients who are acetylcholine receptorantibody positive. It took ten years to do the thymectomy trial and a great deal of persistence. I was not on the leadership team of the trial but was a participating site at the University of Kansas, and I watched with anticipation as the trial unfolded. All of the investigators met at the time the data was unveiled. I attended the meeting in Oxford, England when Drs. Wolfe, Kaminski, and Cutter revealed the findings of the study and it was clearly positive in favor of thymectomy.7 I was glad to be proven wrong. With the positive study results, and long-term 5-year follow-up results of subjects on the trial ${ }^{8}$, we were able to update the practice parameter. ${ }^{9}$

This shows the power of remaining skeptical on treatments that some consider established with poor data to support their conclusions and it shows the power of an academic and international community to tackle the toughest problems that many seem unsolvable. I am proud to be a part of this story.

Dr. Newsom-Davis died tragically in a car accident in Europe when he was driving to a site in Romania to get them up and started in the thymectomy trial. Drs. Wolfe, Kaminski (neurologists), Dr. Cutter (statistician) and Dr.
Fred Jaretski (cardiothoracic surgeon at Columbia in NYC) led the study to its completion. Dr. Jaretski also passed away of natural causes before the study results were unveiled.

\section{References}

1. Gronseth GS, Barohn RJ. Practice parameter: thymectomy for autoimmune myasthenia gravis (an evidencebased review): report of the Quality Standards Subcommittee of the American Academy of Neurology. Neurology 2000;55:7-15

2. Wolfe GI, Herbelin L, Nations SP, Foster B, Bryan WW, Barohn RJ. Myasthenia gravis activities of daily living profile. Neurology. 1999;52(7):1487-1489. doi:10.1212/ wnl.52.7.1487

3. Jaretski A, Barohn RJ, Ernstoff RM, Kaminski HJ, Keesey JC, Penn AS, Sanders DB. Task Force of the Medical Scientific Advising Board of the Myasthenia Gravis Foundation of America. Myasthenia Gravis: Recommendations for clinical research standards. Neurology 2000;55:16-23.

4. Wolfe GI, Barohn RJ, Foster BM, Jackson CE, Kissel JT, Day JW, Thornton CA, Nations SP, Bryan WW, Amato AA, Freimer ML, Parry GJ, Mendell JR. Randomized, controlled trial of intravenous immunoglobulin in myasthenia gravis. Muscle \& Nerve 2002; 26:549-552.

5. McQuillen MP, Leone MG. A treatment carol: thymectomy revisited. Neurology 1977;27:1103-1106.

6. Lanska DJ. Indications for thymectomy in myasthenia gravis. Neurology 1990;40:1828-1829.

7. Wolfe GI, Kaminski HJ, Aban IB, et al; on behalf of the MGTX Study Group. Randomized trial of thymectomy in myasthenia gravis. N Engl J Med 2016;375:511-522.

8. Wolfe GI, Kaminski HJ, Aban IB, Minisman G, Kuo HC, Marx A. Long-term effect of thymectomy plus prednisone versus prednisone alone in patients with nonthymomatous myasthenia gravis; 2-year extension of the MGTX randomized trial. Lancet Neurol 2019;18:P259P268.

9. Gronseth GS, Barohn R, Narayanaswami P. Practice advisory: Thymectomy for myasthenia gravis (practice parameter update): Report of the Guideline Development, Dissemination, and Implementation Subcommittee of the American Academy of Neurology. Neurology. 2020;94(16):705-709. 